\title{
Reply to the correspondence letter by Dr. Giuseppe Indolfi "Spontaneous clearance of hepatitis $C$ virus in vertically infected children. Any clue for treatment?"
}

\author{
Susan Farmand • Stefan Wirth • Philipp Henneke
}

Received: 9 September 2011 / Accepted: 9 September 2011 /Published online: 6 October 2011

(C) Springer-Verlag 2011

We thank Giuseppe Indolfi for adding information on factors affecting the overall prognosis of vertical hepatitis $\mathrm{C}$ virus $(\mathrm{HCV})$ infection. We fully agree that their work [1], which we refer to twice in our publication, as well as other studies provide valuable information on the course of $\mathrm{HCV}$ infections in children. However, neither of the published studies is population based. Therefore, cases with high liver function test (LFT) values are probably overrepresented, since they are discovered more easily, and the rate of clearance may be overestimated. Accordingly, the chance of spontaneous HCV clearance and hence the benefit of early treatment remains somewhat uncertain in the individual young child [2]. In our six patients, the combination of the longitudinal course of LFTs plus HCV gene copy number appeared to aid in predicting the chance of viral resolution. As mentioned in our paper, we concur that other features of HCV infection, such as viral genotype and IL28B polymorphisms, contribute to viral resolution in children $[1,3$, 4]. Therefore, information on IL28B polymorphisms in our patients would have been interesting. Yet, given the small number of cases, it would not have allowed for sound conclusions on its role in clearance. Currently, the decision for early versus delayed treatment remains an individual one. Whereas treatment can be delayed until the age of 5 years in most patients, some children with HCV genotype 1a and persistently elevated LFTs without signs of viral clearance may benefit from earlier treatment, as suggested by the work of Bortolotti et al. [1]. Better treatment algorithms can only be developed in multicenter interventional studies of highest quality.

\section{References}

1. Bortolotti F, Verucchi G et al (2008) Long-term course of chronic hepatitis $\mathrm{C}$ in children: from viral clearance to end-stage liver disease. Gastroenterology. 2008 Jun;134(7):1900-1907.

2. Hu J, Doucette K et al (2010) Treatment of hepatitis C in children: a systematic review. PLoS One 5(7):e11542

3. Thomas DL, Thio CL et al (2009) Genetic variation in IL28B and spontaneous clearance of hepatitis C virus. Nature 461(7265):798801

4. Ruiz-Extremera A, Munoz-Gamez JA et al (2011) Genetic variation in interleukin 28B with respect to vertical transmission of hepatitis $\mathrm{C}$ virus and spontaneous clearance in HCV-infected children. Hepatology 53(6):1830-1838

S. Farmand $\cdot$ P. Henneke $(\bowtie)$

Freiburg, Germany

e-mail: philipp.henneke@uniklinik-freiburg.de

S. Wirth

Wuppertal, Germany 